\title{
Environmentalist identity and environmental striving
}

\author{
Yoshihisa Kashima ${ }^{1}$ \\ Angela Paladino ${ }^{2}$ \\ Elise A. Margetts ${ }^{1}$
}

1. Melbourne School of Psychological Sciences, The University of Melbourne

2. Department of Management and Marketing, The University of Melbourne

\author{
Correspondence: Yoshihisa Kashima \\ Melbourne School of Psychological Sciences \\ The University of Melbourne \\ Parkville, Vic 3010 \\ Australia \\ Email: ykashima@unimelb.edu.au
}




\begin{abstract}
Environmental identity has emerged as a motivator of a wide range of environmentally significant behaviours. Despite its promise, environmental identity is a complex concept that includes multiple facets and needs further explication. One facet is environmentalist identity, or what it means to be an environmentally friendly person as defined by mundane environmentalism in a given cultural milieu. Another facet is environmental striving, a more personal aspect of environmental identity which may motivate behaviours that go beyond mundane environmentalism. Studies with students and general public suggest that environmentalist identity and striving constitute overlapping, and yet complementary aspects of environmental identity. Environmentalist identity is a motivator of multiple domains of environmental behaviours and embedded in people's worldviews about the natural and social worlds; however, environmental striving is an additional motivator of potentially more costly environmental behaviours, and even more intricately embedded in the views about the natural and social worlds.
\end{abstract}

Word Count: 148 


\section{Environmentalist identity and Environmental Strivings}

\section{Introduction}

The sustenance of the natural environment is a significant issue. Despite the cumulative knowledge about specific environmentally significant behaviours such as recycling (e.g., Schultz, Oskamp, \& Mainieri, 1995; Castro, Garrido, Reis, \& Menezes, 2009), alternative transport use (e.g., Chatterton, Coulter, Musselwhite, Lyons, \& Clegg, 2009), green consumer behaviours (e.g., Sparks \& Shepherd, 1992; see Peattie, 2010, for a review), and environmental activism (e.g., Fielding, McDonald, \& Louis, 2008), there is a widespread recognition that a broad spectrum of environmental behaviours, or environmental lifestyles (e.g., Barr, Shaw, \& Gilg, 2011) needs to be adopted to enable a transition to a sustainable future (e.g., Bratanova, Loughnan, \& Gatersleben, 2012; Stern, 2000; Whitmarsh \& O’Neill, 2010). One factor that gives some hope for this possibility is the interdependence among environmental behaviours. For instance, in Denmark, if someone recycles, he or she is also likely to purchase organic food; if they purchase organic food, they may also use transport other than driving (e.g., Thøgersen \& Ölander, 2006). A similar clustering of environmental behaviours has been observed in the United Kingdom as well (e.g., Barr \& Glig, 2006; Whitmarsh, 2009; Whitmarsh \& O’Neill, 2010). If there are some underlying mechanisms that drive a number of environmental behaviours, it may be possible to facilitate a transition into pro-environmental lifestyles by constructing a socio-cultural context, so that these mechanisms encourage citizens to move in the pro-environmental direction.

One such mechanism is environmental identity as a motivational basis for a broad spectrum of environmental behaviours (e.g., Clayton, 2003, 2012). Whitmarsh and O'Neill's (2010) recent work illustrates this point. They found that those who identify themselves as an environmentally friendly person perform environmentally beneficial behaviours generally, including such a broad set of actions as waste reduction, eco-shopping, as well as domestic 
water and energy conservation. Furthermore, this study showed that environmental identity predicted environmental behaviours better than a widely used measure of environmental worldviews, New Ecological Paradigm (Dunlap, Van Liere, Mertig, \& Jones, 2000). In addition, this and other studies (e.g., Sparks \& Shepherd, 1992; Sparks, Shepherd, \& Frewer, 1995; Terry, Hogg, \& White, 1999) have found that environmental identity contributes to the prediction of environmental intentions and behaviours over and beyond the attitudes, subjective norms, or behavioural control that are included in the theory of planned behaviour (Ajzen, 1991; also see Fishbein \& Ajzen, 2011).

Although the prospect of environmental identity is promising, as Clayton (2012) noted, it is a "diverse and evolving topic (p. 164)." Under the broad definition of environmental identity as a psychological connection between oneself and the nonhuman natural environment (e.g., Clayton, 2003; Mayer \& Franz, 2004; Schultz, 2002; Stets \& Biga, 2003), its conceptualizations and operationalizations vary a great deal. In particular, as noted by Clayton and Opotow (2003; also Clayton, 2012), it seems to include diverse aspects, from those which are under greater socio-cultural influences to others that are likely more personal. This presents a potential for further refinement of the construct of environmental identity.

\subsection{Mundane Environmentalism, Environmentalist Identity, and Environmental Striving}

An example of environmental identity that is likely shaped by socio-cultural forces comes from Whitmarsh and O'Neill's (2010) research, which provided strong evidence for environmental identity's ability to predict a wide range of pro-environmental behaviours. In their instrument called pro-environmental self-identity scale, their respondents were asked to indicate whether they agree or disagree to statements like "I think of myself as an environmentally-friendly consumer" or "being embarrassed to be seen as having an environmentally-friendly lifestyle." Here, they were asked whether they think of themselves as having an "environmentally-friendly lifestyle (reverse coded)." This operationalization of 
environmental identity asks respondents to compare the cultural conception of a person with an "environmentally-friendly lifestyle" and one's own self, and if they are sufficiently similar, one would respond in the affirmative (or vice versa). It taps a psychological link between oneself and a culturally defined notion of "environmentally-friendly" person. In the terms of Turner's (1987) self-categorization theory, those who affirm that they are an "environmentally-friendly person" is categorizing themselves into the social category of "environmentally-friendly person," whose content is largely determined by the cultural understanding about what it means to be "environmentally friendly."

We call such everyday cultural understandings of "environmental friendliness" mundane environmentalism. As a social theorist, Bruno Latour (1998) commented, proenvironmental ideas and practices have been absorbed into the mainstream, and a "green" or pro-environmental lifestyle has come to be endorsed by a large segment of society (e.g., de Groot, Drenthen, \& de Groot, 2011; Strizhakova \& Coulter, 2013), so much so that he called it banalisation. Mundane environmentalism differs from environmentalism in the sense of environmental activism (e.g., Fielding et al., 2008). Whereas environmental activism sits outside the mainstream and seeks to change the status quo, mundane environmentalism is a more everyday notion of living a pro-environmental lifestyle that goes well with the middle class culture of most industrialized countries (e.g., Skogen, 1996). Mundane environmentalism is exhibited by people that Kaiser and Bryka (2011) called environmentalists, which they defined as "persons high in environmental engagement (p. 73)." In this paper, we call the type of environmental identity exhibited by mundane environmentalists environmentalist identity ${ }^{1}$.

To be sure, environmentalist identity can provide guidance for social behaviour by encouraging people to act in line with mundane environmentalism. Those who are identified with this social category of environmentalists in the mundane sense should be motivated to 
perform those behaviours that are part of the prototypical mundane environmentalist (Turner, 1987). However, the down side of this mechanism is that mundane environmentalist identity may not motivate people to perform a behaviour that goes beyond the cultural conception of environmentalism. In fact, Whitmarsh and O’Neill's (2010) findings hint at this possibility. Although they found that environmentalist identity predicted such private sphere actions as waste reduction and water/energy use, its effects did not extend beyond them to other environmentally significant actions (Stern, 2000) such as reducing car use or engaging in political actions. Arguably, mundane environmentalism may include domestic private sphere actions, but does not extend to other actions that are seen to be more environmental activism (e.g., writing to MP, participating in a protest) or more embedded in infrastructure (e.g., not driving is very difficult if one lives far away from public transport).

In this paper, we explore the possibility of another aspect of environmental identity, which may be constrained less by the cultural understanding of mundane environmentalism and which may move people beyond it. We call it environmental striving. It is an aspect of environmental identity broadly conceived, but is aligned with what Emmons (Emmons, 1986, 1989; Emmons \& King, 1988) called personal strivings. He defined personal strivings as "what individuals are characteristically aiming to accomplish through their behaviour or the purpose or purposes that a person is trying to carry out. More crisply, a personal striving is what a person is characteristically trying to do (Emmons, 1986; p. 1059).” It is an individual's important personal goals, which Allport (1937) called "teleonomic description" of one's personality. As such, it is akin to Little's (e.g., 1983, 2007) personal projects, Cantor's (e.g., Cantor \& Langston, 1989; Cantor, Norem, Niedenthal, Langston, \& Brower, 1987) life tasks, and the like. It is that part of an individual which is likely to be based on his or her personal conviction, to be embedded in his or her views of the world, and to drive his or her action regardless of (or even despite) what his or her cultural milieu may permit. 
Environmental strivings may be conceptually closely related to the intrinsic motivation to act pro-environmentally as measured by Pelletier, Tuson, Green-Demers, Noels, and Beaton's (1998) Motivation toward the Environment Scale ${ }^{2}$. Although these constructs pertain to a person's holistic profile of personal goals, we borrow their concepts to describe a specific domain, namely, environmental protection. Thus, environmental strivings are defined as the extent to which the maintenance and improvement of the natural environment is a person's important personal goal in life.

According to the accepted view of goals, wherever those personal goals come from, they would drive behaviours that are seen to facilitate the goal attainment (e.g., Fishbach \& Ferguson, 2007; Gollwitzer \& Moskowitz, 1996; Locke \& Latham, 1990; Pervin, 1989). Likewise, environmental strivings are expected to motivate behaviours that are seen to be instrumental for attaining the goal to maintain or improve the natural environment. What is critical with regard to the current discussion of environmental identity is the following. Even if a given behaviour is seen to be outside the cultural conception of environmentalism, people with strong environmental strivings would be motivated to perform that behaviour to the extent that they see it as instrumental for attaining their goal of environmental protection. In other words, environmental strivings may act as a motivational basis of a spectrum of environmental behaviours that is broader than mundane environmentalism to the extent that they are seen to be conducive to the personal striving for sustainability.

\subsection{Contrasting Environmentalist Identity and Environmental Striving}

Both environmentalist identity and environmental striving are part of one's environmental identity. As Whitmarsh and O’Neill (2010) noted, environmentalist identity is a label used to describe oneself, which help one differentiate oneself from others (i.e., nonenvironmentalist) and draw on the values, beliefs, and norms associated with the label (e.g., protect environment). As we defined environmental strivings, they are one's personal goal 
and as such it is also regarded as an aspect of one's self-concept (Emmons, 1989).

Furthermore, they both have similar motivational consequences, that is, to motivate proenvironmental behaviours. Given the overlap in conceptual domains, we expect environmentalist identity and striving to be correlated. Nonetheless, we also expect there to be some systematic differences that stem from people's views about the social and the natural worlds.

\subsubsection{Views about the Natural World}

Environmentalist identity and environmental striving may differ in their relations to people's views about the natural world. Those who are identified with the natural environment are likely to see that the sphere of human activities and that of nature have a great deal of overlap. This general idea comes from the recent work on self-nature overlap (e.g., Schultz, 2002). Following Aaron and his colleagues' measure of self-other overlap (Aaron, Aaron, \& Smolan, 1992; Aaron, Aaron, Tudor, \& Nelson, 1991), Schultz (2002) developed a graphical measure of self-nature overlap where one circle represents the self and the other circle of the same size represents the natural environment. The two circles are placed relative to each other, such that one depiction that shows them as largely overlapping with each other represents great deal of identification with nature, whereas the other end of this continuum is represented by two circles that are separate from each other. Presumably those who are identified with the natural environment should show greater self-nature overlaps. This would suggest that those with high environmental identifications should regard nature as closely associated with the sphere of human activities.

Those with strong environmental strivings are also likely to show a similar tendency to regard nature as closely associated with the sphere of human activities. However, there may be another dimension of human-nature relationship that distinguishes people with strong environmental strivings. It has to do with the view of nature as something psychologically 
"greater" than humans, and therefore "above" humans in some sense. This sentiment is found in the movement called Deep Ecology, for instance. The philosopher who coined the term, Arne Naess $(1985,1989)$, characterized Deep Ecology's conception of nature as not belonging to humans, but as something "worth defending, whatever the fate of humans (Naess, 1985, p. 268)." In an examination of the concept of self implied in the Deep Ecology movement and philosophy, Bragg (1996) also suggested that the self in this sense is expanded to nature or the biosphere as a whole, underlining the notion that a human being is part of and included in nature. Mathews (2003), an ecological philosopher, echoes this sentiment when she says her view "finds [humans] not in command of the world, but kneeling tenderly at its feet, awaiting its command (p. 1; italics in the original)".

The construal of nature as an existence that encompasses humans is often associated with panpsychism, the idea that psyche exists in all physical matters. In Skrbina's (2009) term, panpsychism is the notion that "[m]ind ... abides everywhere (p. xi)." An example of a conceptual connection between the nature-entails -humans view and panpsychism is provided by Mathews (2003). In her view, panpsychism opens a conceptual possibility for humans to establish deep intersubjective connections with nature and its multitudes. Whether it is an ontological commitment to panpsychism (e.g., Strawson, 2006) or an anthropomorphic understanding of nature (e.g., Waytz, Cacioppo, \& Epley, 2010), by attributing mental states to nature and non-human animals and plants, people may regard these beings as deserving of moral treatment (e.g., Gray, Young, \& Waytz, 2012) and therefore being included in the scope of justice (Opotow, 1993, 1994) or the moral circle (Laham, 2009; Bratanova, Loughnan, \& Gatersleben, 2012). This line of thinking is echoed in popular understandings of James Lovelock's Gaia hypothesis (Lovelock, 1979, 1988), which suggests that the planet Earth as a whole is a life form. Although it is a perspective in Earth System Science (Gribbin 
\& Gribbin, 2009), its popular understandings often merge with panpsychic conceptions of the Earth itself (Turney, 2003).

This line of reasoning resonates well with anthropological research on cultural conceptions of nature. According to a well-known anthropologist, Descola $(2006,2009)$, cultures around the world draw a distinction between the physical and mental domains in nature, that is, the body or physicality consisting of physical materials and the mind or mentality that resides in human and other beings in nature. Nonetheless, cultures differ in whether humans and non-humans are seen to be similar or distinct with regard to physicality or mentality. He argues that Western cultures regard humans and non-humans to be made of similar biological materials (i.e., similar in physicality), but only humans have the mind and their mentality is distinct from non-humans (i.e., distinct in mentality; for a brief review, see Kashima \& Margetts, in press). Panpsychism can be thought of as a view that non-humans have mentality similar to humans. Thus, even in Western cultures, those with strong environmental strivings who hold a view of nature as something above and encompassing humans may regard non-humans as similar to humans not only in physicality, but also mentality. Indeed, there is evidence to suggest that pro-environmental stance is associated with perceived similarity of nonhumans to humans (e.g., Opotow, 1994). However, Opotow (1994) found that it depended on the type of similarity: perceived similarity in complexity was associated with pro-environmental attitudes, though perceived similarity in intelligence was not. In light of this ambiguity, it is worth investigating this question further.

\subsubsection{Views about the Social World}

Environmentalist identity and striving may be also related to views about the social world. Kahan and his colleagues (e.g., Kahan, Braman, Gastil, Slovic, \& Mertz, 2007; Kahan, Jenkins-Smith, \& Braman, 2011; Kahan, Peters, Wittlin, Slovic, Ouellette, Braman, \& Mandel, 2012) suggested that people's views about their social world vary along two 
dimensions of what they called cultural worldviews: hierarchy (vs. egalitarianism) and individualism (vs. communitarianism). Hierarchy represents the extent to which people view their social organization to be hierarchically structured as opposed to the view that all members of the society are equal; individualism regards society as consisting largely of selfmotivated individuals who look after themselves as opposed to the view that a community's needs and well being are not maximized by such individuals. Following Douglas and Wildavsky (1982; Thompson, Ellis, \& Wildavsky, 1990), they suggested hierarchists and individualists are more likely to perceive lower environmental risks than egalitarians and communitarians (i.e., low on hierarchy and individualism, respectively). This is because hierarchists and individualists view the natural environment as staying at a relatively stable equilibrium more or less beneficial for humans. If the natural environment is stable, hierarchists can justify their views of the social world by reaffirming the current hierarchical organization of society. Similarly, individualists can do so by believing that the natural environment will not collapse by laissez-faire pursuit of individual happiness.

This line of reasoning suggests that hierarchy and individualism should relate to environmentalist identity and environmental striving. In particular, those who endorse the current social hierarchy (hierarchists) and those who are in favour of laissez-faire individualism with a small government (individualists) would hold a lower level of environmentalist identity, and similarly a weaker environmental striving. There is empirical evidence consistent with this conjecture. Kahan et al. (2007) found that hierarchy and individualism negatively predicted environmental risk perception, such that hierarchists and individualists tended to underestimate the environmental risks including nuclear power generation, global warming, and environmental pollution generally. A construct related to hierarchy, Social Dominance Orientation (Pratto, Sidanius, Stallworth, \& Malle, 1994), has been shown to predict lower levels of pro-environmental attitudes and behaviour (Clayton, 
2008; Milfont, Richter, Sibley, Wilson, \& Fischer, 2013; Pratto et al., 1994); there is evidence to suggest that collectivism (construed to be the opposite of individualism) is associated with environmental identity (Clayton, 2003). As well, hierarchists and individualists tend to underestimate the scientific consensus of climate change (Kahan et al., 2011) and the risk of climate change (Kahan et al., 2012). Given that environmental risk perceptions often predict intentions to address the risk (e.g., O'Connor, Bord, \& Fisher, 1999), Kahan's cultural cognitions are likely to be associated with broad motivators of environmental behaviours such as environmental identity. To the best of our knowledge, however, this hypothesis has not been investigated with Kahan et al.'s (2007) measures of hierarchy and individualism in the literature.

\subsection{Predicting Environmental Behavioural Intentions}

Both environmentalist identity and environmental strivings should predict a wide range of environmental behaviours and intentions. Nevertheless, they may motivate different domains of environmental behaviours. Past research (e.g., Stern, Dietz, Abel, Guagnano, \& Kalof, 1999; Whitmarsh \& O’Neill, 2010) has found that behaviours that have some thematic similarities (e.g., activism) or behaviours that are performed within similar contexts (e.g., shopping) tend to form clusters, such that those who engage in one behaviour that falls in a given cluster tend to perform other behaviours in the same cluster. One of the main distinctions appears to be whether behaviours are public or private spheres. We select some specific clusters of environmentally significant behaviours to investigate whether they are motivated by environmentalist identity and environmental striving.

\subsubsection{Private Sphere Behaviours}

Private sphere behaviours pertain to "the purchase, use, and disposal of personal and household products that have environmental impact (Stern, 2000, p. 409)." We selected two behaviour clusters, shopping and car use, because Whitmarsh and O'Neill's (2010) 
investigation found that they form two different factors, and that environmentalist identity correlated with shopping, but not with driving. We surmised that this enables us to investigate a potential impact of environmental striving on these behavioural clusters that are known to be differentially correlated with environmentalist identity.

There is a large literature surrounding what may be called green shopping, or behaviours related to recurrent purchases of goods and services that are more environmentally responsible (e.g., Peattie, 2010; Paladino \& Pandit, 2012; Paladino \& Ng, 2013). This cluster of behaviours contrasts with one-off (or less frequent) purchase behaviours of larger goods and services (e.g., household appliances, automobiles; see Stern, 2011; Whitmarsh \& O’Neill, 2010). Although it is well known that different value orientations predict green recurrent shopping, it was Whitmarsh and O'Neill who found environmentalist identity predicted a composite measure of behavioural intentions to engage in green shopping (e.g., eating organic food, avoid eating meat, buy environmentally-friendly products, buy products with less packaging) in the United Kingdom. We attempt to replicate their finding in Australia.

In contrast, driving constitutes another type of environmentally relevant behaviour. Its environmental impact stems from the daily use of what is already purchased, rather than purchasing and consumption behaviour per se (Dietz, Gardner, Gilligan, Stern, \& Vandenbergh, 2009). Although a modification of driving behaviour can have a fairly large effect on greenhouse gas emissions (e.g., Dietz et al.), some aspects of car use are not under people's control. For instance, if public transport is not easily available, or alternative modes of transportation (e.g., cycling, walking) are infeasible, driving may not be a matter of intention, but a necessity for some people living in certain areas especially in suburbs of Australian cities where the current research was conducted (Newton \& Meyer, 2012). In this light, driving is a particularly intriguing behaviour cluster because Whitmarsh and O’Neill 
(2010) found environmentalist identity was not related to intentions to engage in less driving (e.g., walk, cycle or take public transport for short use an alternative to travelling, journeys, share a car journey with someone else). This may be possibly due to the existence of other competing identities such as being a "motorist" (Murtagh, Gatersleben, \& Uzzell, 2012), but may also be due to the relative difficulty of modifying this behaviour because of the relative lack of control over the mode of transportation. Either way, we examine whether environmentalist identity can predict driving (i.e., lesser amount of driving) in Australia, but also explore whether environmental striving can play a role.

\subsubsection{Public Sphere Behaviours}

In contrast, some other environmentally significant behaviours engage with the public sphere, or civic society. Perhaps the most prominent of this type of behaviours is environmental activism. However, we wish to highlight what we call green talk, or ordinary people's voicing of support for environmental policies in their everyday conversations. Although environmental activism has been recognized as a significant topic of investigation from the early days of environmental behavioural research (e.g., McAdam, McCarthy, \& Zald, 1988), little attention has been paid to ordinary people's everyday conversations about environmental policies. Those who do not formally belong to "green" organizations can still voice their support for environmental policies in everyday conversations. Rather than individuals' opinions on typical public opinion surveys, ordinary citizens' everyday discourse in support of environmental policies, or green talk for short, can be an important class of nonactivist environmentally significant behaviours within the public sphere (Stern, 2000). Green talk is less active than the activist behaviours like participating in demonstrations, but it is no less important because it can influence public policies and at least public perceptions of support for public policies. In this sense, it forms a basis of participatory democracy for environmental issues (Brulle, 2010; also see Ockwell, Whitmarsh, \& O’Neill, 2009, for a 
related argument). This type of behaviour can ensure that "environmental concerns are within awareness and may therefore be influential (Stern, 2000, p. 409).” Although past research (e.g., Stern et al., 1999) did not tap this type of discursive behaviour, it may be a significant environmental behaviour, which has hitherto been neglected in research. Just as environmental activism is influenced by environmental identity (Dono, Webb, \& Richardson, 2010; Fielding et al., 2008), so too may be green talk.

\subsubsection{Linking Environmentalist identity and Environmental Striving to Behaviour}

Although environmentalist identity has been shown to correlate with a variety of environmental behaviours, there seems to be a missing conceptual link between the two. That is, in order for the self-cognition that "I am an environmentally friendly person" (i.e., environmentalist identity) to motivate a behaviour, the behaviour must be perceived to be consistent with the notion of "environmentally friendly person". So, for instance, if a person who regards him or herself as "environmentally friendly" does not perceive the purchase of organic food products to be consistent with this identity, there is no reason to expect that this identity would motivate the purchase of organic food. For this reason, we examine whether identity consistency moderates the relationship between identity and behaviour. More specifically, if identity consistency of a given behaviour is high (i.e., the behaviour is seen to be highly consistent with a given identity), environmentalist identity is likely to be more strongly related to the intention to perform that behaviour than if identity consistency is low.

Similarly, environmental striving is likely to motivate a behaviour that is perceived to be able to help achieve the goal of environmental protection and improvement. In other words, a behaviour that is seen to be more helpful (vs. harmful) in achieving the goal of the sustenance and improvement of the natural environment is more likely to be motivated by environmental striving. This theoretical expectation is embodied in most expectancy-value theories of motivation (see Feather, 1982). More specifically, this implies that striving 
instrumentality (i.e., how instrumental a given behaviour is for striving) may moderate the relationship between environmental striving and behaviour. We will examine this possibility.

\section{$1.4 \quad$ Present Research}

This research examines environmentalist identity as a motivator of a broad spectrum of environmentally significant behaviours including green talk, green shopping, and (less) driving. In addition, we propose environmental striving as an additional motivator, which overlaps with but can be empirically differentiated from environmentalist identity. In so doing, we examine how environmentalist identity and environmental striving relate to people's views about the natural and social worlds. We attempt to address these issues by analysing two data sets from different samples: a general public sample in the state of Victoria, Australia, and a student sample from the University of Melbourne in the same state. In particular, we have three broad aims, around which the method and results sections are organized. First, we aim to develop a scale of the new construct, environmental striving, and examine its reliability and relationship with environmentalist identity by using both general public and student samples. Second, we aim to examine the relations of environmental identity and environmental striving with people's views about the natural world in terms of new measures of nature-human relationships and the social world in terms of Kahan et al.'s (2012) hierarchy and individualism by analysing the relevant aspects of the two data sets. Finally, we aim to examine the relations of environmentalist identity and environmental striving with green talk, green shopping, and (less) driving in the general public sample. In so doing, we will explore whether consistency of behaviours with identity (identity consistency) and instrumentality of behaviours for environmental striving (striving instrumentality) can predict environmental behavioural intentions over and beyond the identity and striving themselves.

\section{Method}




\subsection{Participants}

General public and student samples all received a measure of environmentalist identity and environmental striving, but they received somewhat different batteries of measures otherwise. We will characterize each sample and instruments below.

\subsubsection{General Public Sample}

Surveys were mailed individually to 2000 potential respondents residing in Victoria, Australia, with the incentive that those who returned completed surveys had the chance to be randomly selected for one out of 10 available $\$ 50$ shopping vouchers. In total, 1093 surveys were returned. The majority of respondents were aged between 18 and 70 years (11 indicated above 70 years and one who indicated that they were below 18 years), with the most common age groups being between 41 and 55 years (39\%) and between 56 and 70 years (37\%). The sample consisted of more females (67\%) than males (33\%). When asked what country they had spent the largest portion of their life in, $91 \%$ of respondents indicated Australia, with the rest being from Asia (2.5\%), Europe (3\%), Africa (1\%), North America (0.5\%), NZ/Pacific (1.5\%), Dubai (0.1\%) and South America (0.1\%).

\subsubsection{Student Sample}

The student sample consisted of 72 first year undergraduate psychology students from the University of Melbourne. Students were aged between 17 and 30 years with 30 males and 40 females (two not specifying). When asked what country they had spent the largest portion of their life in, 60 students indicated Australia, four indicated the UK, four indicated an Asian country and two indicated New Zealand. Of the students, $67 \%$ lived in a house, $19 \%$ in an apartment and $7 \%$ in a shared house ( $4 \%$ indicated 'other').

\subsection{Measures}

\subsubsection{Demographic Information (both samples)}


Participants were asked a series of demographic questions including gender, age (measured as 6 groups: under 18, between 18-30, 31-40, 41-55, 56-70 and above 70 years), and country they had spent the majority of their lives.

\subsubsection{Environmentalist identity (both samples)}

Four survey items taken from Whitmarsh and O’Neill (2010) were used to measure environmentalist identity. Two questions measured the extent to which participants thought of themselves as environmentally-friendly consumers and someone who is concerned with environmental issues. Two other items asked participants how much they would be embarrassed to be seen as having an environmentally friendly lifestyle as well as the extent to which they would not want their family and friends to think of them as being concerned with environmental issues. Responses were collected on five-point scales anchored by "strongly agree" and "strongly disagree." Cronbach's $\alpha$ was acceptable with .73 for the general public and .72 for the students.

\subsubsection{Environmental Striving (both samples)}

Environmental strivings were measured via four items taken from Emmons (1986): The first item, "One of the objectives that I try to accomplish or attain in my life is to sustain or improve the natural environment and the condition of the planet Earth for future generations", is based on his definition of personal striving. The second and third items, "I feel a lot of joy or happiness when I am successful in sustaining or improving the natural environment" and "I feel a lot of sorrow or unhappiness when I fail to sustain or improve the natural environment," were based on the items used to measure the value of a personal striving. The fourth item, "It is extremely important for me to sustain or improve the natural environment," is Emmons's importance measure. Responses were collected on five-point scales anchored by "strongly agree" and "strongly disagree." Cronbach's $\alpha$ was good with .87 for the general public and .80 for the students. 


\subsubsection{New Ecological Paradigm (NEP; student only)}

Dunlap et al.'s (2000) New Ecological Paradigm scale was administered. The example items include: "One of the worst things about overpopulation is that many natural areas are getting destroyed for development," "I can enjoy spending time in natural settings just for the sake of being out in nature." Cronbach's $\alpha$ was .78 (15 items).

\subsubsection{Similarity between Non-humans and Humans (student only)}

This measure was inspired by Carey (1985). Participants were asked to state the likelihood of non-human beings having some physical or psychological properties that humans are said to or known to have. The non-human beings were: three types of mammals (dogs, lions, and koalas), two types of insects (bees and worms), and two types of plants (flowers and trees). In line with Descola $(2006,2010)$, human-non-human similarity was evaluated on physicality and mentality. First, one item on physicality, taken from Carey (1985), read, "Omenta are yellowish in color, and are flat and thin. Humans have an omentum, and it is found inside a person's body around the abdominal area. How likely is it that each of the following things (i.e., the seven non-human beings) also has an omentum?" A response was made on an 11-point scale ( $0=$ "not at all likely"; $10=100 \%$ likely $)$. Two other items similarly attributed a certain physical characteristic to humans and then asked for a likelihood judgment about each non-human being having the same characteristic: "Humans secrete uric acid crystals," and "Humans require trace amounts of magnesium for reproduction." Five items on mentality had an identical structure, where the abilities to have psychological states were first attributed to humans and the likelihood of non-humans having these abilities was then evaluated on the same 11-point scale. Two items were concerned about experiential abilities ('to experience sensations like pleasure and pain, warm glow of the sun, cold chill of the frost, and so on," "to feel emotions like fear and sadness, pride and happiness.") and two items were about agentic abilities ("to think and plan," "to have 
intentions and to choose to do or not to do things"). Cronbach's $\alpha$ for the items about mammalian physicality (9 items, .90) and mentality (12 items, .93), insect physicality (6 items, .85) and mentality (8 items, .92), as well as plant physicality (6 items, .84) and mentality (8 items, .86) was all high, and therefore averaged to form scales.

\subsubsection{Human-Nature Relationship (general public only)}

Participants were presented with 25 sets of circles and asked to choose which circles best represented their thoughts about the relationship between Humans and Nature (see Figure 1). Each set had a circle labelled ' $H$ ' which represented humans and ' $N$ ' which represented nature. The circles varied in relative sizes (Nature-above-Human: 5 levels) and degree of overlap (Nature-Human Overlap: 5 levels) in a 5 x 5 factorial. One level in relative sizes had a large $\mathrm{N}$ to $\mathrm{H}$ ratio (where $\mathrm{H}$ was about one quarter the size of $\mathrm{N}$ ), a next level a moderate $\mathrm{N}$ to $\mathrm{H}$ ratio (where $\mathrm{H}$ was about half the size of $\mathrm{N}$ ), a middle level where $\mathrm{N}$ and $\mathrm{H}$ were of equal size, a fourth level with a large $\mathrm{H}$ to $\mathrm{N}$ ratio (where $\mathrm{N}$ was about one quarter the size of $\mathrm{H}$ ) and a fifth level with a moderate $\mathrm{H}$ to $\mathrm{N}$ ratio (where $\mathrm{N}$ was about half the size of $\mathrm{H})$. This indicated the extent to which participants regarded Nature to be "greater than" or "above" Humans. The other dimension varied the extent to which $\mathrm{N}$ and $\mathrm{H}$ overlapped with each other: one level presented them as mutually exclusive, another level, overlapping slightly, a middle level, overlapping so there was an equal amount of $\mathrm{H}$ and $\mathrm{N}$ in each circle, a fourth level, substantially overlapping, and a fifth level, completely overlapping. This indicated the extent to which participants regarded Nature to be psychologically close to humans.

\subsubsection{Cultural Worldviews (general public only)}

To measure the cultural worldviews, we used Kahan et al.'s (2012) scale of hierarchyegalitarianism (6 items, Cronbach's $\alpha=.73$ ) and individualism - communitarianism (6 items, Cronbach's $\alpha=.72$ ). Example items include "We have gone too far in pushing equal rights in 
this country (hierarchy)," "Our society would be better off if the distribution of wealth was more equal (egalitarianism; i.e., low hierarchy)," "The government interferes far too much in our everyday lives (individualism)," and "Sometimes government needs to make laws that keep people from hurting themselves (communitarianism; low individualism).” Following Kahan et al., the average egalitarianism scores were subtracted from the average hierarchy scores to compute hierarchy; the average communitarian scores were subtracted from the average individualism scores.

\subsubsection{Environmentally Significant Behavioural Intentions (general public only)}

Three environmentally significant behavioural domains were examined: green shopping, driving, and green talk. Participants were asked to indicate the extent to which they "intend to" carry out a specified behaviour the next time they had the opportunity to do so. Behaviours in the grocery shopping context included items concerning organic goods purchases, meat purchases, using green/environmentally friendly bags and purchasing items with heavy packaging (e.g., "I intend to buy some organic food products"; 4 items, Cronbach's $\alpha=.65)$. The driving context asked participants about driving when grocery shopping, to work, for leisure activities and for short journeys (e.g., "I intend to use a car (as a driver or as a passenger) to go to work"; 4 items, Cronbach's $\alpha=.64)$. In the green talk domain, participants were asked about the likelihood of saying something positive about setting a price on carbon and policies that favour 'green' technologies (e.g., "I intend to say something positive about policies that favour "green" technologies (e.g., solar, wind, and other technologies that do not use fossil fuels such as oil and coal to generate electricity)"; 2 items, Cronbach's $\alpha=.66$ ).

To measure the consistency of a behaviour with the participants' environmentalist identity, they were asked "Are the following things consistent, inconsistent, or having no relevance to being a person who has an environmentally friendly lifestyle," presented with all 
10 of the within-domain behaviours (e.g., "Buying organic food products," "Using a car to go to work," "Saying something positive about policies that favour "green" technologies"), and told to rate each behaviour on a five-point scale anchored by consistent $(=5)$ and inconsistent $(=1)$. In addition, to measure the instrumentality of each behaviour for their environmental striving, they were also asked "Do the following things have a helpful, a harmful, or no effect at all on the chance of being successful in sustaining or improving the natural environment," presented with the behaviours (identically phrased as in the identity consistency), and told to rate how each behaviour on a five-point scale anchored by helpful $(=5)$ and harmful $(=1)$. Cronbach's $\alpha$ was high for identity consistency items for green shopping (.78), driving (.89), and green talk (.75); that for instrumentality items was also high for green shopping (.79), driving (.94), and green talk (.72).

\section{Results}

\subsection{General Characteristics of Environmentalist Identity and Environmental Striving}

Environmentalist identity and environmental striving items were averaged and rescaled to $[0,1]$ range for ease of interpretation. General characteristics of environmentalist identity and environmental striving are reported in Table 1. The distribution of the scales appears to be reasonable, but environmental striving is highly negatively skewed in the student sample (skewness $=-.73$ and significantly different from zero; all others were within an acceptable range). All analyses of this scale were conducted with and without transformation (the scale direction was reversed, natural log was taken, and then the scale direction was again reversed). All significant results remained the same, and therefore only untransformed raw score results are reported.

As expected, for both samples, the mean environmentalist identity was higher than the mean environmental striving, suggesting that environmentalist identity is a more socially accepted stance than environmental striving. As well, environmentalist identity and 
environmental striving were significantly correlated with each other, as well as with gender $($ male $=1$, female $=2)$ in both samples (Table 2$)$. The latter finding is generally in line with the literature on environmental concerns and gender (e.g., Davidson \& Freudenburg, 1996). Given the high correlation between environmentalist identity and environmental striving, in exploring their correlations with the other measures, we computed both bivariate correlations and partial correlations while controlling for the other environmental motivation variable (e.g., controlling for striving when correlating identity, or vice versa).

\subsection{Views about the Natural World}

Table 2 reports correlations and partial correlations of environmentalist identity and environmental striving with the measures of people's views about the natural world. First of all, both environmentalist identity and environmental striving are correlated with NEP. However, when environmentalist identity was partialled out, striving was not significantly correlated with NEP. This suggests that environmental identity is highly related to the paradigm of environmentalism (i.e., new ecological paradigm) as expected, but environmental striving is not uniquely related to it, suggesting that the latter has an aspect that diverges from the paradigmatic notion of environmentalism.

Of greater importance for environmental striving is a feeling of greater similarity and affinity with non-mammalian life forms such as insects and plants (observed in the student sample). In terms both of physicality and mentality, those with stronger environmental striving are more likely to think that human attributes can be generalized to even insects and plants. Furthermore, the link between environmental striving and human-nonhuman similarity appears to be largely due to psychological similarity attributed to nonhumans. The partial correlation of environmental striving with insect mentality and with plant mentality remained significant (.26 and .36 , respectively) when insect physicality was controlled; however, the partial correlation of environmental striving with insect physicality and with 
plant physicality became nonsignificant (.15 and .02 , respectively) when insect mentality was controlled. In contrast, environmentalist identity was not related to the tendency to attribute human-like attributes to insects and plants. This suggests that one of the components of environmental striving that differentiates itself from environmentalist identity, at least in the Australian student sample, may be something like panpsychism (Mathews, 2003; Skrbina, 2009).

Finally, the graphical measure of human-nature relationship (taken in the general public sample) showed somewhat different relations with environmentalist identity and environmental striving. In terms of bivariate and partial correlations, those with higher environmentalist identity tended to see greater overlap between the nature and human spheres (greater nature-human overlap) and see nature as "above" humans (greater nature-abovehuman). Nevertheless, these zero-correlations are somewhat misleading in that they do not take into consideration the correlation between nature-human overlap and nature-abovehuman indices $(r=.34)$. Partial correlation between nature-human overlap and environmentalist identity while controlling for nature-above-human index was significant, $p r$ $=.13$. However, when nature-human overlap was partialed out, nature-above-human index and environmentalist identity was not significantly correlated $(p r=.04, \mathrm{p} .=.197)$, suggesting that environmentalist identity is related to the view of nature that places it above human only through its correlation with nature-human overlap. Turning to environmental striving, like environmentalist identity, it correlated with nature-human overlap; however, it did not correlate with nature-above-human. Given this pattern of correlations, it can be inferred that the correlation between nature-human overlap and nature-above-human did not produce a spurious correlation.

In order to explore these relationships further, we examined an interaction effect of nature-human overlap and nature-above-human on environmentalist identity and 
environmental striving by conducting a regression analysis with nature-human overlap, nature-above-human, and their interaction (main effect terms were standardized and then interaction term was computed by multiplying the two). For environmentalist identity, naturehuman overlap was the only significant predictor, whereas for environmental striving, there was a significant effect of overlap, which also interacted with nature-above-human. Figure 2 illustrates the pattern. Regardless of the level of nature-above-human, nature-human overlap positively predicted the striving, but striving was even stronger when the nature was seen to be "above" humans. This is an intriguing pattern - those who personally strive for the natural environment may do so for some spiritual reason. That is, they may be striving to reach or save nature, which is placed above and beyond the realm of humans.

\subsection{Views about the Social World}

First, we examined bivariate and partial correlations of environmentalist identity and environmental striving with hierarchy and individualism (Kahan et al., 2012; Table 3; taken in the general public sample). As expected, those with higher environmentalist identity and stronger striving tend not to endorse hierarchical or individualistic views about the social world. However, when striving was partialed out, the relationship between identity and individualism became non-significant, suggesting that environmental striving has a stronger association with anti-laissez-faire individualism with stronger emphasis on a communitarian view of the social world. We further used a regression analysis to examine the additive effects of hierarchy and individualism. Consistent with the correlations, only hierarchy significantly predicted environmentalist identity, whereas both hierarchy and individualism predicted environmental striving (Table 4).

\subsection{Predicting Behavioural Intentions to Green Talk, Green Shop, and Drive Less}

Each domain of behavioural intentions (green talk, green shopping, and driving less) was predicted by both environmentalist identity and identity consistency of the behaviours as 
well as environmental striving and striving instrumentality of the behaviours in the general public sample. In particular, we included six predictors in a simultaneous regression analysis for each behaviour domain: environmentalist identity, identity consistency, and their interaction as well as environmental striving, striving instrumentality, and their interaction. The main effect variables were standardized and multiplied to compute the interaction terms. Each interaction term has only one degree of freedom, and therefore a t-test for this term is equivalent to an F-test for this term when a hierarchical regression analysis is used (squared tvalue equals the F-value).

We expected that environmentalist identity would motivate green talk and green shopping, but would not motivate less driving as much. There were two reasons for this expectation. First, as we noted earlier, environmentalist identity should motivate those behaviours that an environmentally friendly person is seen to be typically engaged in. Our data suggest that green talk and green shopping were clearly seen to be consistent with environmentalist identity (see Table $1 ; M=.72,95 \% \mathrm{CI}[.71, .74]$ and $M=.77,95 \% \mathrm{CI}[.76,79]$ in $[0,1]$, respectively), whereas driving less was seen to be least consistent $(M=.55$, $95 \% \mathrm{CI}[.53, .56]$ in $[0,1])$. The latter was different from the former two. Therefore, green talk and green shopping are more likely motivated by environmentalist identity, whereas driving less may not be. Second, green talk is the least costly, whereas green shopping is perhaps somewhat more costly, and driving less is most costly within the context of Australia. Consistent with these expectations, $\mathrm{R}^{2}$ is greatest for green talk, followed by green shopping, and least for driving (Table 5).

Consistent with the previous research (Whitmarsh \& O’Neill, 2010), environmentalist identity and identity consistency predicted green talk and green shopping, though they failed to predict driving less (again this was consistent with Whitmarsh and O'Neill's research in the UK; Table 5). Interestingly, environmental striving and instrumentality predicted all three 
domains of behaviours (Table 5). The fact that they predicted intention to drive less suggests that environmental striving has an ability to motivate even a relatively more difficult environmentally significant behaviour.

We also explored the interaction effects of identity and consistency as well as striving and instrumentality. Identity $\mathrm{x}$ consistency interactions were significant for green talk and green shopping; striving $\mathrm{x}$ instrumentality interaction was significant only for green shopping. Note that the standardized regression coefficients for the interaction effects were positive (Table 5), suggesting that the combination of high values in both the main effects tended to predict the criterion over and above the main effects. More specifically, the pattern of the interaction effects suggest that those who are high on identity and who also regard performing a given domain of behaviours as consistent with one's identity are most likely to perform the behaviours (green talk and green shop). Likewise, those who have stronger striving and who also regard performing behaviours in a given domain as more likely to help their striving were more likely to intend to engage in the domain of action (green shop). Although these patterns are in line with the theoretical expectations, only three out of six interactions were significant. Further investigation seems in order.

At this point, it is prudent to check to see if content overlap between the items of environmentalist identity and green shopping may be responsible for the above findings. Note that one of the items for environmentalist identity asked them whether they would consider themselves to be an "environmentally friendly consumer." We recomputed environmentalist identity score by excluding this item and conducted analogous regression analyses. Table 6 reports their results, which largely replicate the results reported in Table 5. The only difference is that the identity $\mathrm{x}$ consistency interaction effect for green shopping became nonsignificant. All in all, it seems safe to conclude that the content overlap does not alter the inference drawn. 


\section{Discussion}

The present research examined the viability of environmentalist identity and environmental striving as two motivators of a broad spectrum of environmentally significant behaviours. We theorized that environmentalist identity is one's identification with a cultural conception of environmentalism, whereas environmental striving is one's personal striving to maintain and protect the natural environment. Both are aspects of environmental identity broadly conceived, and therefore significantly related to each other. And yet they appear to have somewhat different antecedents and consequences. On the one hand, environmentalist identity draws significantly on people's views about the nature and the social world - those who prefer a more egalitarian (non hierarchical) social structure and those who regard the nature as psychologically close to humans tend to hold a stronger environmentalist identity. On the other hand, environmental striving has a basis similar to environmentalist identity, and yet seems to go a step further. Those with stronger environmental strivings tend to regard the nature as an existence that is greater than, and more inclusive of, humans, and consider nonhuman beings to possess psychological make-up relatively more similar to humans.

Furthermore, environmentalist identity drives typical environmentalist actions such as green talk and green shopping, but environmental striving additionally motivates less driving - a more costly behaviour that is more constrained by the infrastructure in Australia, where this research was conducted.

However, these findings should be regarded as preliminary. We have investigated only three classes of behaviours as potentially motivated by environmentalist identity and environmental strivings, and future research should expand the scope of research to include behaviours other than driving less as instances of costly behaviours. Indeed, whether environmental striving can motivate a broader range of costly behaviours needs to be investigated further. In total, it is fair to say that environmentalist identity is clearly an 
important contender as a motivator of broad environmental behaviours. In addition, environmental striving appears to be worthy of further consideration.

Environmental striving provides a potentially useful perspective on the promotion of environmental protection and improvement. If indeed environmental striving is a strong motivator of a wide range of behaviours, it makes sense to try to cultivate it. Given that it is embedded in views of nature as above humans and nonhuman entities with humanlike mental characteristics (e.g., beliefs, intentions, feelings of pain), it is possible that environmental strivings can be strengthened by promoting these views about nature. For instance, some features of nature can invoke awe as a strong positive emotion (Shiota, Keltner, \& Mossman, 2007), which tends to facilitate the social transmission of the information that invokes awe in people (Berger \& Milkman, 2012). Awe is an emotional experience that can also inspire the impression of nature as above human. Awe inspiring experiences of nature may enhance people's environmental striving. Another strategy to enhance environmental strivings may be to cultivate the view that nonhuman creatures have humanlike mentality. Consistent with this, Tam, Lee, and Chao's (2013) recent work has found that anthropomorphism of nature can enhance pro-environmental behavioural intentions. Investigations of correlates of environmental strivings may help us generate innovative strategies for furthering environmental protection and improvement.

Despite its promise, environmental striving as a personal motivator may go only so far. There would be an obvious contextual and infrastructure constraint to environmental behaviour. To use driving as an example, it would be extremely difficult, if not impossible, to avoid driving a car to go anywhere if one lives in the outback of Australia where the nearest public transport may be hundreds of kilometres away (e.g., Kaiser \& Schultz, 2009). Even if the contextual constraint is not so extreme, it may be very costly to reduce driving, and such cost is a significant impediment to some environmental behaviour (e.g., Kaiser, Byrka, \& 
Hartig, 2010). In short term, therefore, environmental strivings would surely have limiting conditions. High costs or strong contextual constraints of pro-environmental behaviour would limit the influence of environmental strivings. Nonetheless, environmental strivings may still provide a motivational basis for behaviours that are designed to modify those contextual constraints, so as to enable the performance of pro-environmental behaviour (e.g., starting a grassroots campaign to bring public transport closer to home, or even move to a place where public transport is closer). They may even motivate innovation - new ways to sustain the natural environment that are outside the scope of mundane environmentalism. Further research needs to shed light on such possibilities.

At this point, it is useful to conjecture how environmentalist identity and environmental striving relate to environmental activist identity (e.g., Dono et al., 2010; Fielding et al., 2008), another culturally significant aspect of environmental identity. We suggest that mundane environmentalism and environmental activism constitute complementary subsets of environmentalism. Whereas mundane environmentalism overlaps greatly with the mainstream of many industrialized (and even industrializing) societies, environmental activism situates itself outside the mainstream and attempts to change the society. Identifications with mundane environmentalism and environmental activism, therefore, are different from each other in that they characterize self-categorizations with those distinctive social categories. Nonetheless, environmental striving does not have to be aligned with either social category, and may be aligned with either or both. If mundane environmentalism and environmental activism differentiates environmentalism along the political dimension of mainstream vs. activism, environmental striving is agnostic to the political dimension. Whether those with strong environmental striving engage with environmental activism would in part depend on whether they believe activism is instrumental for their goal. As such, there is no contradiction in the possibility that 
environmental activist identity drives costly environmental behaviours such as political actions (e.g., Fielding et al., 2008) whereas environmental striving can drive non-political costly behaviour such as driving less.

In addition, the present research explored the possibility that identity consistency and striving instrumentality play a role in motivating people's environmentally significant behaviours. As hypothesized, people are more likely to intend to perform behaviours that are seen to be consistent with their environmentalist identity and instrumental for their environmental striving. These effects were found over and above the effects of environmentalist identity and environmental striving per se. Again, identity consistency did not have a significant association with intentions to drive less; however, striving instrumentality did have a significant association with all three domains of behaviours: green talk, green shopping, and driving less.

Nonetheless, further examination of the role of consistency and instrumentality is warranted. It seems more theoretically reasonable to expect an identity $\mathrm{x}$ consistency interaction effect, as well as a striving $\mathrm{x}$ instrumentality interaction effect, on intentions as we noted earlier (see Feather's, 1982, edited volume on expectancy-value model). Yet, this was found only for three out of six interaction effects examined.

Assuming that the theoretical basis for the expectancy value model is sound, we offer two methodological explanations for this less than perfect support. First, the measurement procedure for consistency and instrumentality can be improved. It is possible that our wording of consistency (behaviour being consistent vs. inconsistent with a person with environmentally friendly lifestyle) and instrumentality (behaviour being helpful vs. harmful for sustaining or improving the natural environment) may not have been most appropriate. Different wordings may need to be explored. For instance, for identity consistency, an alternative may be: "Are the following things consistent or inconsistent with being a person 
who has an environmentally friendly lifestyle? If you think they have no relevance to being this type of a person whatsoever, select the midpoint marked as 'no relevance'." For striving instrumentality, an alternative may be: "Do the following things help you to sustain or improve the natural environment or hinder you from doing so? If you think they have no effect, select the midpoint marked as 'no effect'."

Second, as Busemeyer and Jones (1983) pointed out, the effect of a multiplicative component such as identity $\mathrm{x}$ consistency and striving $\mathrm{x}$ instrumentality interactions is rather difficult to detect if they include measurement errors. Given the complexity of the issues of scaling and testing of multiplicative models (e.g., Ajzen \& Fishbein, 2008), it is useful to further explore these issues in future research.

All in all, environmentalist identity seems to be a useful concept in considering the social dynamics of environmentally significant behaviours. It is embedded within people's worldviews about the natural environment and social world, and drives behaviours that are generally in line with the conception of environmentalism widely held within their cultural milieu. However, environmental striving appears to add further complexity to people's environmental identity that is relevant for the environmental issues and behaviours. It seems even more intricately woven into people's conviction and personal commitment, providing a potential to go beyond what is culturally accepted. This new construct may help us have a better handle of the meaning of environmental identity that is so central to the contemporary thinking of environmental behaviour. 
Table 1. General characteristics of the key variables

\begin{tabular}{|c|c|c|c|c|}
\hline & $M$ & SD & Min & $\operatorname{Max}$ \\
\hline \multicolumn{5}{|l|}{ General Public } \\
\hline Environmentalist Identity & .71 & .14 & .13 & 1.00 \\
\hline Environmental Striving & .65 & .17 & .00 & 1.00 \\
\hline Nature- Human Overlap & .65 & .33 & .00 & 1.00 \\
\hline Nature above Human & .61 & .26 & .00 & 1.00 \\
\hline Hierarchy (Kahan et al.) & .44 & .18 & .00 & 1.00 \\
\hline Individualism (Kahan et al.) & .54 & .16 & .00 & 1.00 \\
\hline Green Talk Intention & .54 & .25 & .25 & 1.00 \\
\hline Green Talk Consistency & .72 & .24 & .00 & 1.00 \\
\hline Green Talk Instrumentality & .67 & .15 & .00 & 1.00 \\
\hline Green Shopping Intention & .58 & .19 & .00 & 1.00 \\
\hline Green Shopping Consistency & .77 & .18 & .00 & 1.00 \\
\hline Green Shopping Instrumentality & .79 & .15 & .00 & 1.00 \\
\hline Driving (less) Intention & .24 & .21 & .00 & 1.00 \\
\hline Driving (less) Consistency & .55 & .28 & .00 & 1.00 \\
\hline Driving (less) Instrumentality & .64 & .27 & .00 & 1.00 \\
\hline \multicolumn{5}{|l|}{ Student } \\
\hline Environmentalist Identity & .71 & .14 & .38 & 1.00 \\
\hline Environmental Striving & .62 & .16 & .06 & 1.00 \\
\hline NEP (Dunlap et al.) & .71 & .09 & .49 & .92 \\
\hline Mammal Physicality & .77 & .16 & .33 & 1.00 \\
\hline Mammal Mentality & .78 & .20 & .24 & 1.00 \\
\hline Insect Physicality & .39 & .21 & .00 & 1.00 \\
\hline Insect Mentality & .46 & .25 & .00 & 1.00 \\
\hline Plant Physicality & .26 & .21 & .00 & 1.00 \\
\hline Plant Mentality & .22 & .21 & .00 & 1.00 \\
\hline
\end{tabular}

Note: All are rescaled from 0 to 1 . 
Table 2. Correlations and partial correlations of environmentalist identity and environmental striving with a variety of measures of views about the natural environment and the social world.

\begin{tabular}{|c|c|c|}
\hline & $\begin{array}{l}\text { Environmentalist } \\
\text { Identity }\end{array}$ & $\begin{array}{c}\text { Environmental } \\
\text { Striving }\end{array}$ \\
\hline \multicolumn{3}{|l|}{ General Public } \\
\hline Gender $(\mathrm{M}=1 ; \mathrm{F}=2)$ & $.12 * *(.05)$ & $.14 *\left(.08^{*}\right)$ \\
\hline Age & $.04(.03)$ & $.02(-.01)$ \\
\hline Income & $-.07 *(.01)$ & $-.06(.05)$ \\
\hline Nature- Human Overlap & $.15 * *(.09 *)$ & $.12 * *(.04)$ \\
\hline Nature above Human & $.09 * *(.09 *)$ & $.03(-.03)$ \\
\hline Hierarchy (Kahan et al.) & $-.27 * *(-.14 * *)$ & $-.26 * *(-.13 * *)$ \\
\hline Individualism (Kahan et al.) & $-.11 * *(.02)$ & $-.20 * *(-.17 * *)$ \\
\hline \multicolumn{3}{|l|}{ Student } \\
\hline Gender $(\mathrm{M}=1 ; \mathrm{F}=2)$ & $.31 * *(.20)$ & $.25 *(.06)$ \\
\hline NEP (Dunlap et al.) & $.48^{* *}\left(.26^{*}\right)$ & $.45^{* *}(.19)$ \\
\hline Mammal Physicality & $.13(.04)$ & $.16(.10)$ \\
\hline Mammal Mentality & $.14(-.01)$ & $.23(.18)$ \\
\hline Insect Physicality & $.08(-.17)$ & $.33^{* *}\left(.36^{* *}\right)$ \\
\hline Insect Mentality & $.25 *(.02)$ & $.39 * *(.31 *)$ \\
\hline Plant Physicality & $.06(-.13)$ & $.26^{*}\left(.28^{*}\right)$ \\
\hline Plant Mentality & $.27 *(-.00)$ & $.43 * *(.35 * *)$ \\
\hline
\end{tabular}

Note: $* *$ p. $<.01 ; *$ p. $<.05$. For general public, $\mathrm{df}=1093$ for correlations and 1090 for partial correlations. For students, $\mathrm{df}=67$ for correlations and 66 for partial correlations. Within parentheses are partial correlations that control for the other environmental motivation variable. Correlation with age is not reported for the student sample due to small variance in age. We did not measure income for the student sample. 
Table 3. Unstandardized regression coefficients, $R^{2}$, and $F$ values for regression analyses predicting environmentalist identity and striving by nature-human overlap and inclusion.

\begin{tabular}{lcc}
\hline & Identity & Striving \\
\hline $\mathrm{R}^{2}$ & $.02^{* *}$ & $.02^{* *}$ \\
$\mathrm{~F}$ & 8.59 & 8.73 \\
\hline Overlap & $.02^{* *}$ & $.03^{* *}$ \\
Nature above Human & .01 & -.00 \\
Overlap x Nature above Human & .00 & $.01^{*}$ \\
\hline
\end{tabular}

Note: ${ }^{* *}$ p. $<.01 ; *$ p. $<.05 . \mathrm{dfs}=3,1053$. All predictors are standardized; all criterion variables are rescaled from 0 to 1 .

Table 4. Unstandardized regression coefficients, $\mathrm{R}^{2}$, and $\mathrm{F}$ values for regression analyses predicting environmentalist identity and striving by nature-human overlap and inclusion.

\begin{tabular}{lcc}
\hline & Identity & Striving \\
\hline $\mathrm{R}^{2}$ & $.07^{* *}$ & $.08^{* *}$ \\
$\mathrm{~F}$ & 42.90 & 49.25 \\
\hline Individualism & -.02 & $-.14^{* *}$ \\
Hierarchy & $-.26^{* *}$ & $-.21^{* *}$ \\
\hline
\end{tabular}

Note: $* *$ p. $<.01 ; *$ p. $<.05 . \mathrm{dfs}=4,1088$; All predictors are standardized; all criterion variables are rescaled from 0 to 1 . 
Table 5. Standardized regression coefficients, $R^{2}$, and $F$ values from regression analyses predicting intentions to green talk, green shop, and drive using the original environmentalist identity measure.

\begin{tabular}{lcccccc}
\hline & Green Talk & $\begin{array}{c}\text { Green } \\
\text { Shopping }\end{array}$ & $\begin{array}{c}\text { Driving } \\
\text { (less) }\end{array}$ \\
\hline $\mathrm{R}^{2}$ & $.43^{* *}$ & & $.35^{* *}$ & & $.05^{* *}$ & \\
$\mathrm{~F}$ & 133.74 & & 96.85 & & 8.54 & \\
\hline & $\beta$ & $p$ & $\beta$ & $p$ & $\beta$ & $p$ \\
\hline Identity & .17 & .00 & .13 & .00 & .06 & .13 \\
Striving & .20 & .00 & .22 & .00 & .08 & .03 \\
Consistency & .20 & .00 & .18 & .00 & .06 & .10 \\
Instrumentality & .29 & .00 & .24 & .00 & .11 & .00 \\
Identity x Consistency & .09 & .00 & .07 & .01 & .03 & .31 \\
Striving x Instrumentality & .01 & .68 & .06 & .03 & -.00 & .93 \\
\hline
\end{tabular}

Note: ${ }^{* *}$ p. $<.01 ; *$ p. $<.05 . \mathrm{dfs}=6,1086$. All predictors and criteria are standardized.

Table 6. Standardized regression coefficients, $\mathrm{R}^{2}$, and $\mathrm{F}$ values from regression analyses predicting intentions to green talk, green shop, and drive using a modified environmental identity index.

\begin{tabular}{lcccccc}
\hline & Green Talk & $\begin{array}{c}\text { Green } \\
\text { Shopping }\end{array}$ & \multicolumn{2}{c}{$\begin{array}{c}\text { Driving } \\
\text { (less) }\end{array}$} \\
\hline $\mathrm{R}^{2}$ & $.43^{* *}$ & & $.34^{* *}$ & & $.05^{* *}$ & \\
$\mathrm{~F}$ & 136.46 & & 92.18 & & 8.51 & \\
\hline & $\beta$ & $p$ & $\beta$ & $p$ & $\beta$ & $p$ \\
\hline Identity & .18 & .00 & .04 & .19 & .04 & .34 \\
Striving & .20 & .00 & .27 & .00 & .10 & .01 \\
Consistency & .19 & .00 & .18 & .00 & .06 & .09 \\
Instrumentality & .29 & .00 & .26 & .00 & .11 & .00 \\
Identity x Consistency & .10 & .00 & .04 & .16 & .01 & .83 \\
Striving x Instrumentality & .01 & .56 & .08 & .00 & .00 & .80 \\
\hline
\end{tabular}


Figure 1. Graphical measure of human-nature relationship

Nature above

Humans

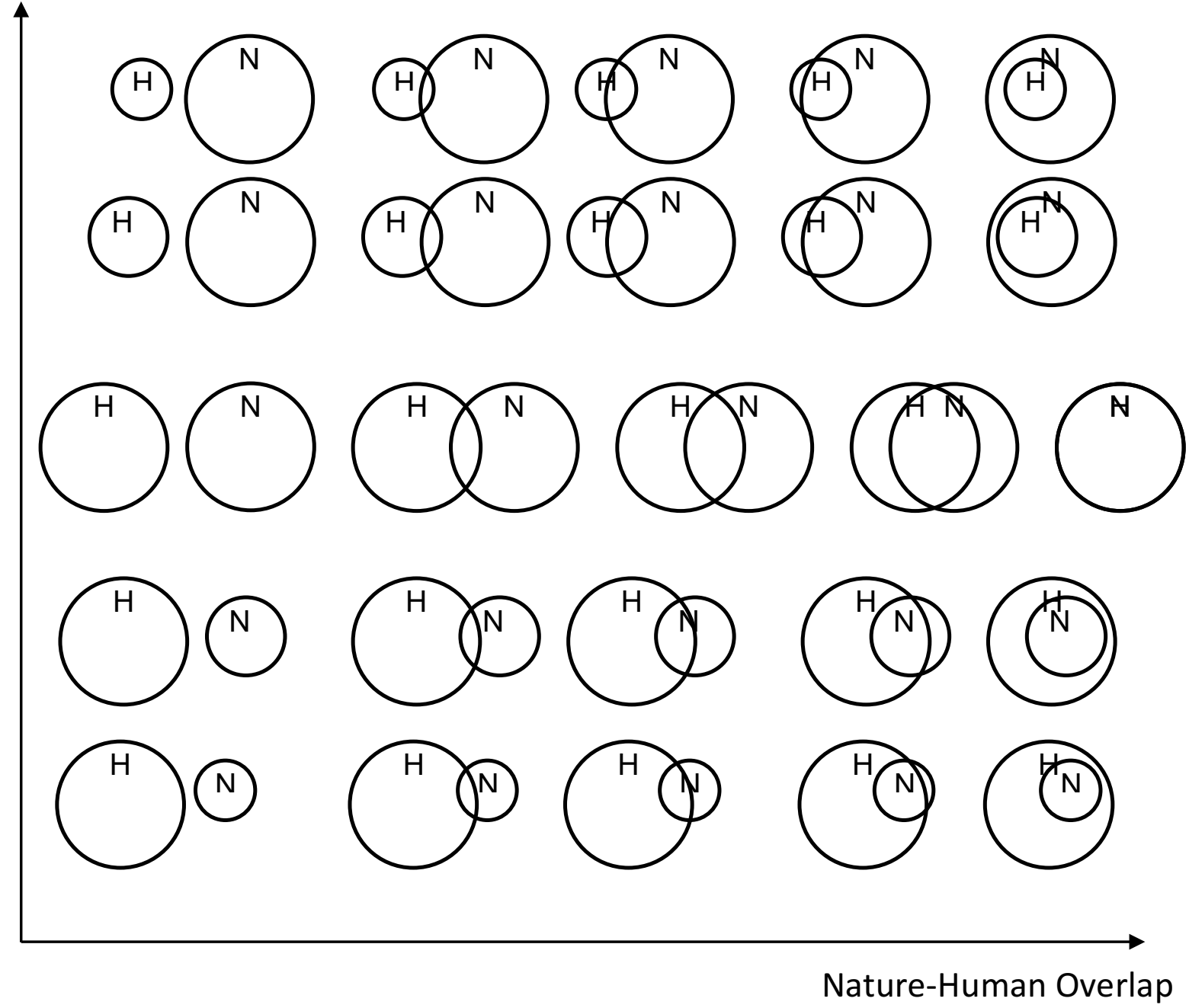

Note: Participants were given the following instructions: "Many cultural traditions have long histories of thinking about what it means to be human and human's place in the universe. Although this is often considered to be a question for philosophers and great thinkers, it is also a question that many of us ponder about from time to time. We are interested in finding out your thoughts about human's place in nature. In the picture below, a circle marked ' $\mathrm{H}$ ' represents Humans and a circle marked 'N' represents Nature. Which of the following depiction best represents your thoughts about the relationship between Humans and Nature? Please tick one." The arrowed dimensions and their labels were not presented to the participants. 
Figure 2. Environmental striving as a function of Nature-Human Overlap and Nature above Human

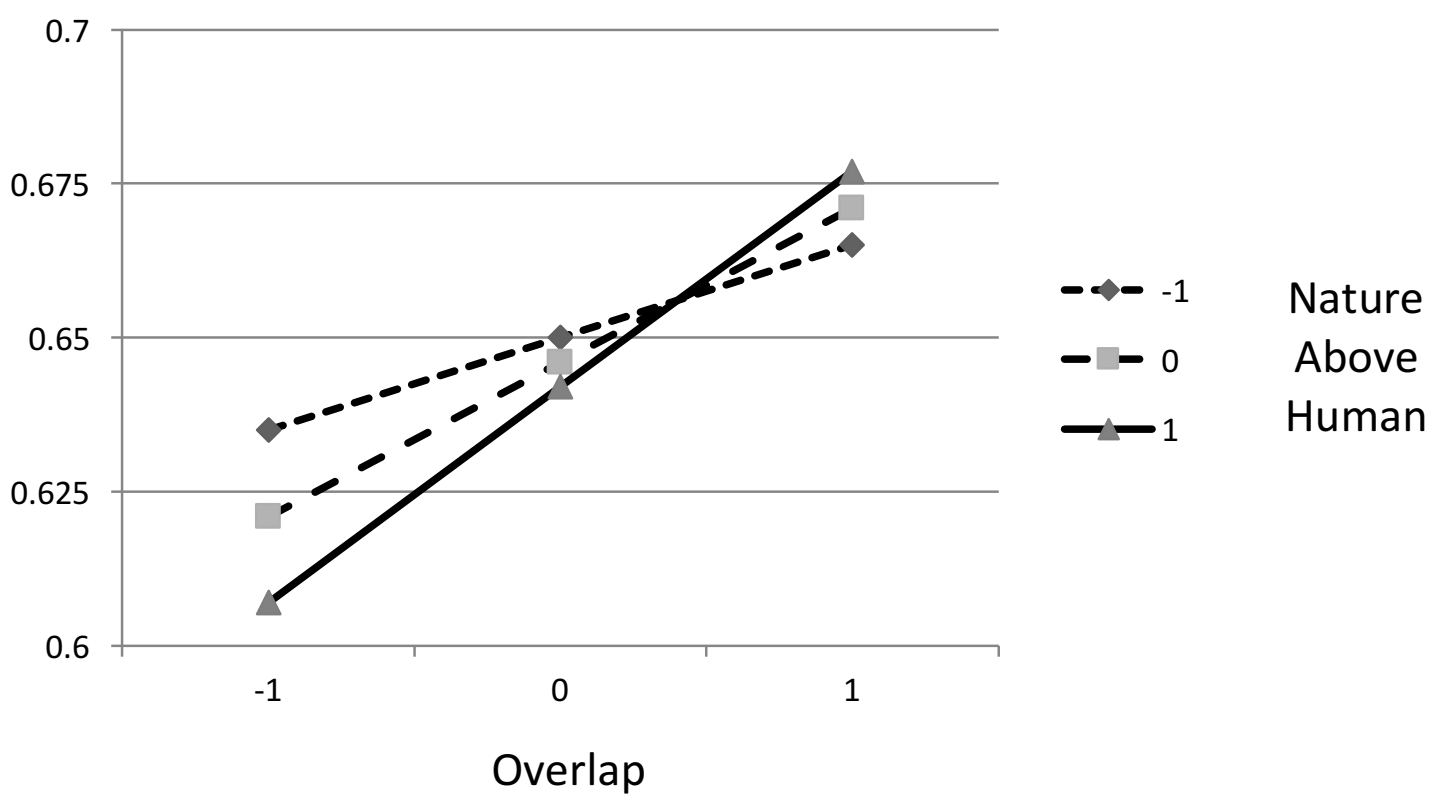


Figure 3. Identity $x$ Consistency and Striving $x$ Instrumentality Interaction on Intentions
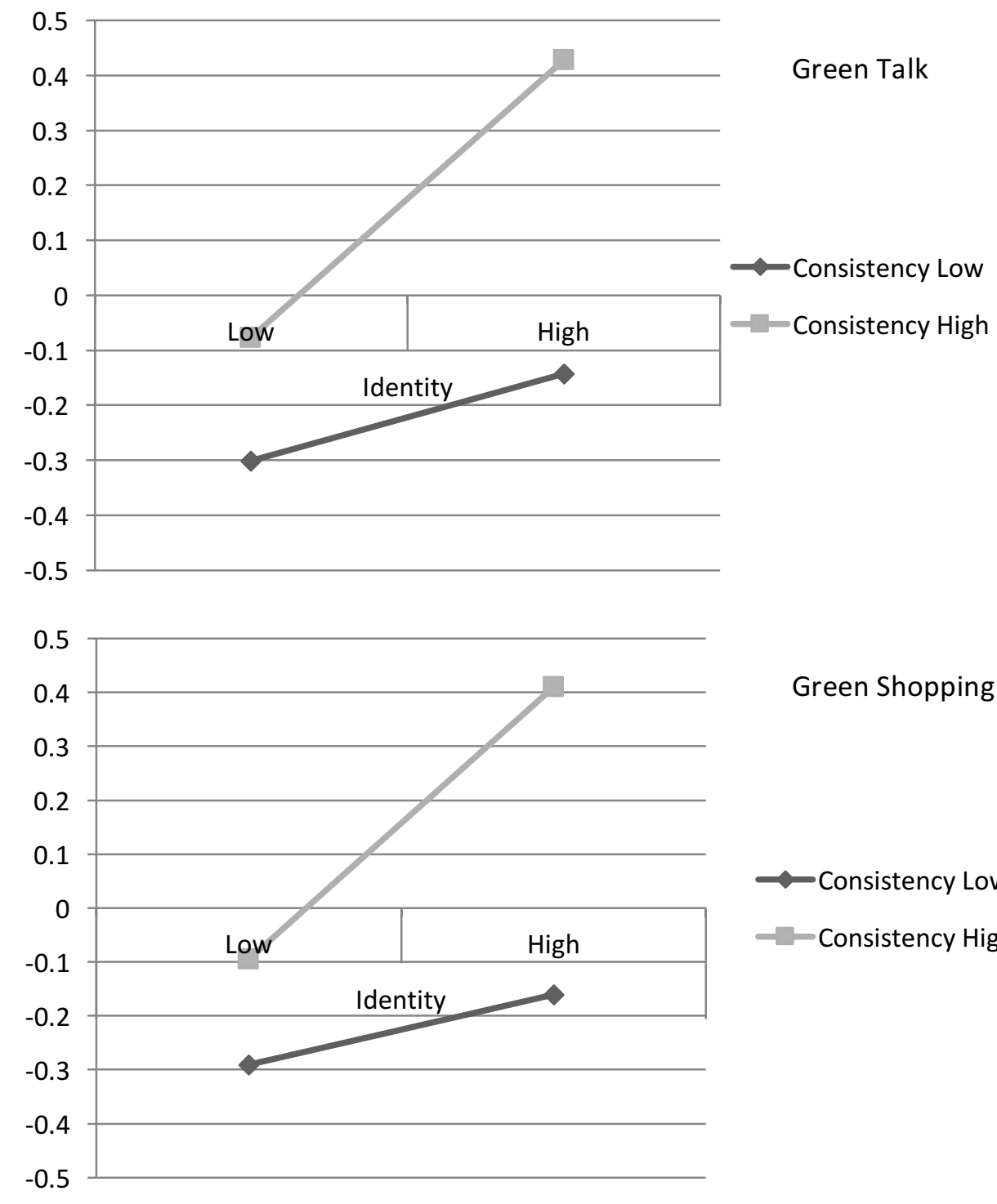

Green Shopping

$\sim$ Consistency Low

-Consistency High

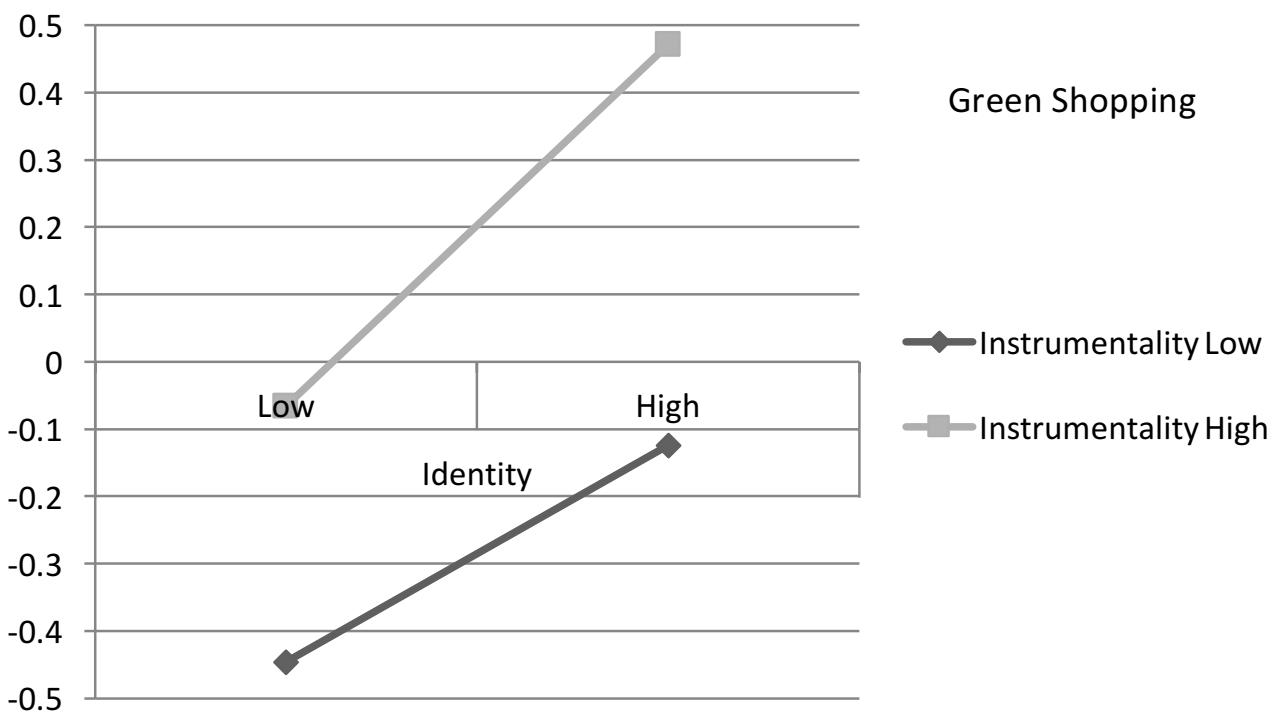




\section{Author Note}

The research reported in this paper was supported by a grant from the Interdisciplinary Seed Funding Scheme of the University of Melbourne, as well as by a Discovery grant from the Australian Research Council (DP130102229) to Y. Kashima and A. Paladino. We thank two anonymous reviewers' very helpful and constructively critical comments on an early version of the paper, which helped us refine our conceptualization of environmentalist identity and environmental striving. Please send correspondence to Yoshihisa Kashima, Melbourne School of Psychological Sciences, The University of Melbourne, Parkville, Vic 3010, Australia (Email: ykashima@,unimelb.edu.au). 


\section{End Note}

1. We thank an anonymous reviewer for suggesting the term, "environmentalist identity," to capture our point.

2. We thank the same anonymous reviewer for making this point as well. 


\section{References}

Aron, A., Aron, E. N., \& Smollan, D. (1992). Inclusion of other in the self scale and the structure of interpersonal closeness. Journal of Personality and Social Psychology, 63, $596-612$.

Aron, A., Aron, E. N., Tudor, M.,\&Nelson, G. (1991). Close relationships as including other in the self. Journal of Personality and Social Psychology, 60, 241-253.

Ajzen, I. (1991). The theory of planned behavior. Organizational Behavior and Human Decision Processes, 50, 179-211.

Ajzen, I., \& Fishbein, M. (2008). Scaling and testing multiplicative combinations in the expectancy-value model of attitudes. Journal of Applied Social Psychology, 38, 22222247.

Allport, F. (1937). Teleonomic description in the study of personality. Character and Personality, 5, 202-214.

Barr, S., \& Gilg, A. (2006). Sustainable lifestyles: Framing environmental action in and around the home. Geoforum, 37, 906-920.

Barr, S., Shaw, G., \& Gilg, A. W. (2011). The policy and practice of 'sustainable lifestyles'. Journal of Environmental Planning and Management, 54, 1331-1350.

Berger, J., \& Milkman, K. L. (2012). What makes online content viral? Journal of Marketing Research, XLIX, 192-205.

Bragg, E. A. (1996). Towards Ecological Self: deep ecology meets constructionist self-theory. Journal of Environmental Psychology, 16, 93-108.

Bratanova, B., Loughnan, S., \& Gatersleben, B. (2012). The moral circle as a common motivational cause of cross-situational pro-environmentalism. European Journal of Social Psychology, 42, 539-545. 
Brulle, R. J. (2010). From environmental campaigns to advancing the public dialog:

Environmental communication for civic engagement. Environmental Communication, 4, $82-98$.

Busemeyer, J. R. \& Jones, L. E. (1983). Analysis of multiplicative combination rules when the causal variables are measured with error. Psychological Bulletin, 93, 549-562.

Cantor, N. \& Langston, C. A. (1989). Ups and downs of life tasks in a life transition. . In L. A. Pervin (Ed.), Goal concepts in personality and social psychology (pp. 127-167). Hillsdale, NJ: Erlbaum.

Cantor, N., Norem, J. K., Niedenthal, P. M., Langston, C. A., \& Brower, A. M. (1987). Life tasks, self-concept ideals, and cognitive strategies in a life transition. Journal of Personality and Social Psychology, 53, 1178-1191.

Carey, S. (1985). Conceptual change in childhood. Cambridge, MA: MIT Press.

Castro, P., Garrido, M., Reis, E., \& Menezes, J. (2009). Ambivalence and conservation behaviour: An exploratory study on the recycling of metal cans. Journal of Environmental Psychology, 29, 24-33, 1649-026.

Chatterton, , T.J., Coulter, A., Musselwhite, C., Lyons, G., and Clegg, S. (2009) Understanding how transport choices are affected by the environment and health: Views expressed in a study on the use of carbon calculators. Public Health, 123, $45-49$.

Clayton, S. (2003). Environmental identity: A conceptual and an operational definition. In S. Clayton \& S. Opotow (Eds.), Identity and the natural environment (pp. 45-65). Cambridge, MA: The MIT Press.

Clayton, S. (2008). Attending to identity: Ideology, group membership, and perceptions of justice. In K. Hegtvedt \& J. Clay-Warner (Eds.), Advances in group processes: Justice (pp. 241-266). Bingley, UK: Emerald. 
Clayton, S. (2012). Environment and identity. In S. D. Clayton (Ed.), The Oxford handbook of environmental and conservation psychology (pp. 164-180). Oxford, UK: Oxford University Press.

Clayton, S. \& Opotow, S. (2003). Introduction. In S. Clayton \& S. Opotow (Eds.), Identity and the natural environment (pp. 1-24). Cambridge, MA: The MIT Press.

Davidson, D. J. \& Freudenburg, W. R. (1996). Gender and environmental risk concerns: A review and analysis of available research. Environment and Behavior, 28, 302-339.

de Groot, M., Drenthen, M., \& de Groot, W. T. (2011). Public visions of the human/nature relationship and their implications for environmental ethics. Environmental Ethics, 33, 2544.

Descola, P. (2006). Beyond nature and culture. Proceedings of the British Academy, 139, $137-155$.

Descola, P. (2009). Human natures. Social Anthropology, 17, 145-157.

Dietz, T., Gardner, G. T., Gilligan, J., Stern, P. C., \& Vandenbergh, M. P. (2009). Household actions can provide a behaviour wedge to rapidly reduce US carbon emissions. Proceedings of National Academy of Science, 106, 18452-18456.

Dono, J., Webb, J., \& Richardson, B. (2010). The relationship between environmental activism, pro-environmental behaviour and social identity. Journal of Environmental Psychology, 30, 178-186.

Douglas, M. \& Wildavsky, A. (1982). Risk and culture. Berkeley: University of California Press.

Dunlap, R. E., van Liere, K. D., Mertig, A. G., Jones, R. E. (2000). Measuring endorsement of the new ecological paradigm: A revised NEP scale. Journal of Social Issues, 56, $425-$ 442. 
Emmons, R. A. (1986). Personal strivings: An approach to personality and subjective wellbeing. Journal of Personality and Social Psychology, 51, 1058-1068.

Emmons, R. A. \& King, L. A. (1988). Conflict among personal strivings: Immediate and long-term implications for psychological and physical well being. Journal of Personality and Social Psychology, 54, 1040-1048.

Emmons, R. A. (1989). The personal striving approach to personality. In L. A. Pervin (Ed.), Goal concepts in personality and social psychology (pp. 87-126). Hillsdale, NJ: Erlbaum. Feather, N. (Ed.) (1982). Expectations and actions: Expectancy-value models in psychology. Hillsdale, NJ: Lawrence Erlbaum.

Fielding, K. S., McDonald, R., \& Louis, W. R. (2008). Theory of planned behaviour, identity and intentions to engage in environmental activism. Journal of Environmental Psychology, 28, 318-326.

Fishbach, A. \& Ferguson, M. J. (2007). The goal construct in social psychology. In A. Kruglanski \& E. T. Higgins (Eds.), Social psychology: Handbook of basic principles $\left(2^{\text {nd }}\right.$ ed., pp. 490-515). New York: The Guilford Press.

Fishbein, M. \& Ajzen, I. (2010). Predicting and changing behaviour: The reasoned action approach. New York: Psychology Press.

Gollwitzer, P. M. \& Moskowitz, G. B. (1996). Goal effects on thought and behaviour. In E. T. Higgins \& A. W. Kruglanski (Eds.), Social psychology: Handbook of basic principles (pp. 361-399). New York: The Guilford Press.

Gray, K., Young, L., \& Waytz, A. (2012). Mind perception is the essence of morality. Psychological Inquiry, 23, 101-124.

Gribbin, J., \& Gribbin, M. (2009). James Lovelock: In search of Gaia. Princeton, NJ: Princeton University Press. 
Kahan, D. M., Braman, D., Gastil, J., Slovic, P., \& Mertz, C. K. (2007). Culture and identityprotective cognition: Explaining the white-male effect in risk perception. Journal of Empirical Legal Studies, 4, 465-505.

Kahan, D. M., Peters, E., Wittlin, M., Slovic, P., OUellette, L. L., Braman, D., \& Mandel, G. (2012). The polarizing impact of science literacy and numeracy on perceived climate change risks. Nature Climate Change, 2, 732-735.

Kahan, D. M., Jenkins-Smith, H., \& Braman, D. (2011). Cultural cognition of scientific consensus. Journal of Risk Research, 14, 147-174.

Kaiser, F. G., \& Byrka, K. (2011). Environmentalism as a trait: Gauging people's prosocial personality in terms of environmental engagement. International Journal of Psychology, $46,71-79$.

Kaiser, F. G., Byrka, B., \& Hartig, T. (2010). Reviving Campbell's paradigm for attitude research. Personality and Social Psychology Review, 14, 351-367.

Kaiser, F. G. \& Schultz, P. W. (2009). The attitude-behavior relationship: A test of three models of the moderating role of behavioral difficulty. Journal of Applied Social Psychology, 39, 186-207.

Kashima, Y. \& Margetts, E. (in press). On human-nature relationship. In P. Bain, Vaes, J., Leyens, J.-P. (Eds.), Humanness and dehumanization. Psychology Press.

Laham, S. (2009). Expanding the moral circle: Inclusion and exclusion mindsets and the circle of moral regard. Journal of Experimental Social Psychology, 45, 250-253. DOI: 10.1016/j.jesp.2008.08.012

Latour, B. (1998). To modernise or ecologise? That is the question. In B. Braun \& N. Castree (Eds.), Remaking reality: Nature at the millennium (pp. 221-242). London, UK: Routledge. Little, B. R. (1983). Personal projects: A rationale and method for investigation. Environment and Behavior, 15, 273-309. 
Little, B. R. (2007). Personality science and personal projects: Six impossible things before breakfast. Journal of Research in Personality, 39, 4-21.

Locke, E. A., \& Latham, G. P. (1990). A theory of gaol setting and task performance. Upper Saddle River, NJ: Prentice-Hall.

Lovelock, J. E. (1979). Gaia: A new look at life on earth. Oxford, UK: Oxford University Press.

Lovelock, J. E. (1988). The ages of Gaiai: A biography of our living earth. Oxford, UK: Oxford University Press.

Mathews, F. (2003). For love of matter: A contemporary panpsychism. Albany, NY: State University of New York Press.

Mayer, F. S., \& Frantz, C. M. (2004). The connectedness to nature scale: A measure of individuals' feeling in community with nature. Journal of Environmental Psychology, 24, $503-515$.

McAdam, D., McCarthy, J.D., \& Zald, M. N. (1988). Social movements. In N. J. Smelser (Ed.), Handbook of sociology (pp. 695-737). Newbury Park, CA: Sage.

Milfont, T. L., Richter, I., Sibley, C. G., Wilson, M. S., \& Rischer, R. (2013). Environmental consequences of the desire to dominate and be superior. Personality and Social Psychology Bulletin, 39, 1127-1138.

Murtagh, N., Gatersleben, B., \& Uzzell, D. (2012). Multiple identities and travel mode choice for regular journeys. Transportation Research Part F, 15, 514-524.

Naess, A. (1985). Identification as a source of deep ecological attitudes. In M. Tobias (Ed.), Deep ecology (pp. 256-270). San Diego, CA: Avant Books.

Naess, A. (1989). Ecology, community, and lifestyle: Outline of an ecosophy. (Tr. By D. Rothenberg) Cambridge, UK: Cambridge University Press. 
Newton, P., \& Meyer, D. (2012). The determinants of urban resource consumption. Environmental and Behavior, 44, 107-135. DOI: 10.1177/0013916510390494

Ockwell, D., Whitmarsh, L., \& O’Neill, S. (2009). Reorienting climate change communication for effective mitigation: Forcing people to be green or fostering grassroots engagement? Science Communication, 30, 305-327.

O’ Connor, R. E., Bord, R. J., \& Fisher, A. (1999). Risk perceptions, general environmental beliefs, and willingness to address climate change. Risk Analysis, 19, 461-471.

Opotow, S. (1993). Animals and the scope of justice. Journal of Social Issues, 49, 71-85.

Opotow, S. (1994). Predicting protection: Scope of justice and the natural world. Journal of Social Issues, 50, 49-63.

Paladino, A. \& Ng, S. (2013). Examining the influences of intentions to purchase green mobile phones among young consumers: An empirical analysis. Environmental Education Research, 19, 118-145.

Paladino, A. \& Pandit, A. (2012). Emerging competitive tools for renewable electricity retailers: Service branding. Energy Policy, 45, 378-388.

Peattie, K. (2010). Green consumption: Behavior and norms. Annual Review of Environment and Resources, 35, 195-228.

Pelletier, L. G., Tuson, K. M., Green-Demers, I., Noels, K., \& Beaton, A. M. (1998). Why are you doing things for the environment? The motivation toward the environment scale (MTES). Journal of Applied Social Psychology, 28, 437-468.

Pervin, L. A. (1989). Goal concepts in personality and social psychology: A historical introduction. In L A. Pervin (Ed.), Goal concepts in personality and social psychology (pp. 1-17). Hillsdale, NJ: Erlbaum. 
Pratto, F., Sidanius, J., Stallworth, L. M., \& Malle, B. F. (1994). Social dominance orientation: A personality variable predicting social and political attitudes. Journal of Personality and Social Psychology, 67, 741-763.

Schultz, P. W. (2002). Inclusion with nature: Understanding human-nature interactions. In P. Schmuck \& P. W. Schultz (Eds.), The psychology of sustainable development (pp. 61-78). New York: Kluwer.

Schultz, P. W., Oskamp, S., \& Mainieri, T. (1995). Who recycles and when? A review of personal and situational factors. Journal of Environmental Psychology, 15, 105-121.

Shiota, M. N., Keltner, D., \& Mossman, A. (2007). The nature of awe: Elictors, appraisals, and effects on self-concept. Cognition and Emotion, 21, 944-963.

Skogen, K. (1996). Young environmentalists: Post-modern identities or middle-class culture? The Sociological Review, 44, 452-473.

Skrbina, D. (2009). Introduction. In D. Skrbina (Ed.), Mind that abides: Panpsychism in the new millennium (xi-xxiv). Amsterdam: John Benjamins Publishing Company.

Sparks, P., \& Shepherd, R. (1992). Self-identity and the theory of planned behaviour: assessing the role of identification with green consumerism. Social Psychology Quarterly, 55(4), 388-399.

Sparks, P., Shepherd, R., \& Frewer, L. J. (1995). Assessing and structuring attitudes toward the use of gene technology in food production: the role of ethical obligation. Basic and Applied Social Psychology, 16(3), 267-285.

Stern, P. C. (2000). Toward a coherent theory of environmentally significant behaviour. Journal of Social Issues, 56, 407-424.

Stern, P. C. (2011). Psychological contributions to limiting climate change. American Psychologist, 66, 303-314. 
Stern, P. C., Dietz, T., Abel, T., Guagnano, G. A., \& Kalof, L. (1999). A value-belief-norm theory of support for social movements: The case of environmentalism. Human Ecology Review, 6, 81-97.

Stets, J. E., \& Biga, C. F. (2003). Bringing identity theory into environmental sociology. Sociological Theory, 21, 398-423.

Strawson, G. (2006). Realistic monism: Why physicalism entails panpsychism. Journal of Consciousness Studies, 13, 3-31.

Strizhakova, Y., \& Coulter, R. A. (2013). The "green" side of materialism in emerging BRIC and developed markets: The moderating role of global cultural identity. International Journal of Research in Marketing, 30, 69-82.

Tam, K.-P., Lee, S.-L., \& Chao, M. M. (2013). Saving Mr. Nature: Anthropomorphism enhances connectedness to and protectiveness toward nature. Journal of Experimental Social Psychology, 49, 514-521.

Terry, D. J., Hogg, M. A., \& White, K. M. (1999). The theory of planned behaviour: self identity, social identity and group norms. British Journal of Social Psychology, 38, 225244.

Thøgersen, J. \& Ölander, F. (2006). The dynamic interaction of personal norms and environmental-friendly buying behaviour: A panel study. Journal of Applied Social Psychology, 36, 1758-1780.

Thompson, M., Ellis, R., \& Wildavsky, A. (1990). Cultural theory. Boulder, CO: Westview Press.

Turner, J. C. (1987). Rediscovering the social group: A self-categorization theory. Oxford, UK: Blackwell.

Turney, J. (2003). Lovelock and Gaia: signs of life..Cambridge, UK: Icon Books. 
Waytz, A., Cacioppo, J., \& Epley, N. (2010). Who sees human? The stability and importance of individual differences in anthropomorphism. Perspectives on Psychological Science, 5, 219-232.

Whitmarsh, L. (2009). Behavioural responses to climate change: Asymmetry of intentions and impacts. Journal of Environmental Psychology, 29, 13-23.

Whitmarsh, L. \& O’Neill, S. (2010). Green identity, green living? The role of self-identity in determining consistency across-diverse pro-environmental behaviours. Journal of Environmental Psychology, 30, 305-314. 


\section{University Library}

\section{- M M I N E R VA A gateway to Melbourne's research publications}

Minerva Access is the Institutional Repository of The University of Melbourne

Author/s:

Kashima, Y;Paladino, A;Margetts, EA

Title:

Environmentalist identity and environmental striving

Date:

2014

Citation:

Kashima, Y., Paladino, A. \& Margetts, E. A. (2014). Environmentalist identity and environmental striving. Journal of Environmental Psychology, 38, pp.64-75. https:// doi.org/10.1016/j.jenvp.2013.12.014.

Persistent Link:

http://hdl.handle.net/11343/113588 